\section{The relationship between body mass index and lifestyle in a Brazilian adult population: a cross-sectional survey}

\author{
Relação entre índice de massa corporal e estilo \\ de vida em uma população adulta do Brasil: \\ um estudo transversal
}

\footnotetext{
${ }^{1}$ Faculdade de Nutrição, Universidade Federal de Goiás, Goiânia, Brasil. 2 Faculdade de Saúde Pública, Universidade de São Paulo, São Paulo, Brasil. 3 Faculdade de Medicina, Universidade Federal de Goiás, Goiânia, Brasil.

Correspondence M. R. G. Peixoto Faculdade de Nutrição, Universidade Federal de Goiás.

Rua 49, Quadra C-2, Lote 2, Goiânia, GO

74810-039, Brasil.

hbpeixoto@uol.com.br
}

\begin{abstract}
This study focused on adult obesity prevalence in Goiânia, Goiás State, Brazil, and the association between socio-demographic variables, lifestyle, physical activity, eating habits, and food consumption frequency and body mass index (BMI). A cross-sectional study was conducted in 2001 with a sample of 1,252 individuals from 20 to 64 years of age. The association between sociodemographic variables, lifestyle, food consumption, and physical activity and BMI was evaluated by hierarchical multiple linear regression analysis. Obesity prevalence was $10.7 \%$ in men and $13.9 \%$ in women. In males, age, income, and meat consumption showed a positive association with BMI, while physical activity during leisure time and commuting and the habit of eating $\geq 4$ meals per day were inversely associated with BMI. In women, positively associated factors were age, no smoking, and no meat consumption; in contrast, consumption of grains was inversely associated with BMI. High obesity prevalence was observed; active lifestyle coupled with ingestion of more grains and less meat appeared to protect against increased BMI.
\end{abstract}

Food Consumption; Physical Activity; Obesity; Life Style
Maria do Rosário Gondim Peixoto 1

Maria Helena D'Aquino Benício 2

Paulo César Brandão Veiga Jardim ${ }^{3}$

\section{Introduction}

The rapid increase in obesity among the world's population has become a major public health problem, affecting both developed and developing countries.

According to the World Health Organization's multi-center study entitled Monitoring of Trends and Determinants in Cardiovascular Diseases (MONICA), including 48 population groups in 23 countries (1983-1986), 50 to $75 \%$ of adults aged 35 to 64 had body mass index (BMI) $\geq 25 \mathrm{~kg} / \mathrm{m}^{2}$. Obesity prevalence was some $15 \%$ for males and $22 \%$ for females, but with considerable variability within and between countries 1 .

In Brazil, according to data from the Family Budget Survey (POF 2002-2003) 2, some 40.6\% of adults had excessive body weight. Comparing data from the POF 2002-2003 with those from the National Study on Family Expenditure (ENDEF 1974-1975), over the course of 30 years the percentage of obese adults nearly doubled (from 5.7 to $10.9 \%)$. This increase occurred in all socioeconomic strata but was proportionally higher in low-income families 2,3 .

This increased obesity prevalence overloads health services, since obesity is frequently associated with diabetes mellitus, dyslipidemia, and arterial hypertension, thus favoring the occurrence of cardiovascular diseases 4,5,6.

The development of obesity involves multiple factors, such as food consumption, patterns 
of physical activity, social and environmental variables, and individual susceptibility determined by genetic and biological factors 1 . The rapid increase in world obesity prevalence points to behavioral changes in the $20^{\text {th }}$ century as the main cause. Activities that formerly required high energy expenditure have been replaced by the ease offered by urbanization and industrial and technological progress, leading in turn to lower energy consumption at work, during commuting, and in domestic and leisure activities. Compounding factors in this decreased energy expenditure include globalization of eating habits that favor obesity due to the dissemination of refined and processed foods, rich in fat and simple sugars and served in ever- growing portions 1 .

However, various studies have shown that factors involved in the genesis of obesity act in different ways, according to the population and social groups in which they are studied $7,8,9$. The objective of the current study were thus to measure the prevalence of excess weight and obesity in the adult population in the city of Goiânia, Goiás State, Brazil, associated with variables related to socio-demographic conditions, lifestyle, physical activity, eating frequency and habits, and BMI.

\section{Material and methods}

The study used data from the Survey on Prevalence and Knowledge of Arterial Hypertension and Selected Risk Factors in a Region of Brazil 10. The project was approved and funded by the Brazilian National Research Council (CNPq) and was conducted by members of the Arterial Hypertension League at the Federal University in Goiás (UFG), in partnership with the Federal University in Mato Grosso (UFMT). The larger study was a cross-sectional, population-based study in the capital cities of these two States and in two cities in the interior of Goiás and Mato Grosso. The current article is limited to data collected in Goiânia from June to December 2001.

\section{Sample}

The size of the sample in Goiânia was calculated by considering a population of 1,004,098 inhabitants, the overall prevalence of arterial hypertension in Brazil ( $20 \%$ of the adult population) 11 , $95 \%$ confidence interval $(95 \% \mathrm{CI})$, and a $10 \%$ estimated error. The required sample $(n=1,534)$ was increased by $30 \%$ to compensate for losses ( $\mathrm{n}=1,994)$.

Among the losses ( $n=540 ; 27.1 \%), 121$ addresses were classified as nonexistent (the ad- dress was not located or the individual no longer lived at that address). Other houses $(n=419)$ were located, but in most of these cases no interview could be performed since the residents refused to answer the questions. Other less frequent causes of losses were empty houses or the impossibility of locating the residents after three visits on different days and at different times.

The sample thus included 1,454 individuals greater than 18 years of age of both sexes, noninstitutionalized, and residing in the urban area (72.9\% of the total sample and $95 \%$ of the required sample). Only 1,252 ranging in age from 20 to 64 years were analyzed in this study. This sample allows estimating the prevalence of overweight and obesity for men and women, with a margin of error of $3 \%$ and $2 \%$, respectively. Considering a two-tailed $\alpha$ of 0.05 and $\beta$ of 0.10 , the sample allowed detecting a correlation of approximately 0.15 for women and men separately 12 .

Houses were selected by two-stage probabilistic sampling of clusters. The first stage consisted of identifying 115 census tracts as defined by the National Census Bureau (IBGE) and used in the National Household Sample Survey (PNAD, 1998) in the urban area of Goiânia. The second stage was the selection of households, considering the number of households in each census tract and the total sample size. Starting from the calculation of sample size per census tract, households were chosen by lot in a random and systematic manner.

To avoid information problems among interviewees, only one resident per household was chosen to be interviewed, among household members $>18$ years. Pregnant women and mothers of infants less than six months of age were excluded to avoid data interpretation errors.

Data were collected by previously trained interviewers (undergraduate students in nursing and nutrition). The interviewers used a questionnaire tested in a pilot study. All the equipment used was calibrated on a regular basis, and the protocol was approved by the Research Ethics Committee of the UFG University Hospital.

\section{Study variables}

\section{- Socio-demographic variables}

Sex, age (in complete years, classified in the age brackets 20-24, 25-34, 35-44, 45-54 and 55-64 years); parity (total number of children born to each woman interviewed); presence of spouse/ partner (yes/no); schooling (in years: $0-3$; 4-8; and $\geq 9$ ); family income (monthly per capita income, in quartiles); and information on healthy eating in the previous year (yes/no). 


\section{- Lifestyle variables}

Smoking, alcohol intake, and physical activity were evaluated on the basis of a group of questions standardized by the Pan-American Health Organization in 1997 in the Integrated NonCommunicable Disease Prevention in the Americas (CARMEN) protocol 13. Concerning smoking, participants were classified into three groups: never smoked, former smokers (having stopped smoking more than six months previously), and smokers (current or having stopped less than six months previously). Alcohol consumption was evaluated by questions on alcoholic beverage intake (yes/no).

\section{- Physical activity variables}

Occupational physical activity and leisure-time physical activity were estimated by dividing this category into four classes according to intensity of effort: (1) sedentary; (2) light; (3) moderate; and (4) intense. In this study, classes 3 and 4 were combined due to the small number of individual in class 4 .

In order to evaluate physical activity involved in commuting to work, individuals were asked whether they walked or rode a bicycle and how long they spent at this activity per day. They were then grouped into classes that spent less versus more than 15 minutes/day walking or bicycling to and from work.

Leisure-time physical activity was classified in four groups: (1) sedentary - no physical activity, only reading or watching television; (2) light - occasional physical activities like walking, riding a bicycle, or performing light exercise; (3) moderate - regular physical activity (running, gymnastics, swimming, team sports); (4) intense - heavy weekly training or regular participation in sports contests. Due to the small number of individuals in the latter group, groups three and four were combined for analysis.

Sedentary behavior was evaluated by the selfreported number of hours watching TV per day: (1) $<2$; (2) 2 to 4 ; (3) 4 to 6 ; and (4) $>6$ hours. Individuals were then grouped into two classes: those who watched TV for less than 6 hours versus more than 6 hours/day.

\section{- Food intake variables}

To evaluate food consumption, a questionnaire on frequency of simple food intake over the previous year was used. Food items were classified in 8 intake categories: $\left(f_{1}\right)$ never; $\left(f_{2}\right)<$ once a month; $\left(f_{3}\right) 1$ to 3 times a month; $\left(f_{4}\right)$ once a week; $\left(f_{5}\right) 2$ to 3 times a week; $\left(f_{6}\right) 4$ to 6 times a week; $\left(f_{7}\right)$ once a day; $\left(f_{8}\right)$ twice or more a day. An appropriate methodology was used to allow frequency of food consumption in the previous year to be treated as a quantitative variable 14 .

The questionnaire on the frequency of consumption also included questions on the following nutritional practices: use of sweeteners; removal of fat from meat; removal of chicken skin; eating while watching TV; and number of meals per day.

The list of the foods investigated contained 140 items; those with similar composition were combined in a single item, totaling 68 food items distributed among the following groups: milk and dairy products; meat; eggs; fat; grains; bread and tubers; green leafy vegetables; fruits, vegetables, beverages; pastries and salty snacks; and sugar and sweets. This food list was based on information on food consumption in the county of Goiânia, as obtained by the Multi-center Study on Food Consumption 15.

To control for recent changes in food intake patterns, interviewees were asked whether they had changed their diet for health reasons within the previous 12 months (yes/no)

\section{- Anthropometric variables}

All anthropometric measurements were performed according to standard procedures 16. An electronic Plenna scale, Giant Lithium model (Plenna, São Paulo, Brazil) with $150 \mathrm{~kg}$ capacity and $100 \mathrm{~g}$ precision was used to weigh subjects. Individuals were weighed barefoot and wearing light clothing. Height was measured with a portable Seca stadiometer 206 model (Seca, Hamburg, Germany) with $0.1 \mathrm{~cm}$ precision. Waist circumference (WC) was measured with a tape measure at the mean point between the anterior superior iliac crest and the last rib at the end of gentle expiration. The cut-off points of WC for women were $<80 \mathrm{~cm}, 80-88 \mathrm{~cm}$, and > $88 \mathrm{~cm}$, and $<94 \mathrm{~cm}, 94-102 \mathrm{~cm}$, and $>102 \mathrm{~cm}$ for men and were classified, accordingly as normal, increased, and greatly increased 1 .

\section{- Outcome variation}

The primary final outcome of this study was BMI, calculated as weight $(\mathrm{kg}) /$ height squared $\left(\mathrm{m}^{2}\right)$. BMI values were classified as: $<18.5 \mathrm{~kg} / \mathrm{m}^{2}$ (underweight); $18.5-24.9 \mathrm{~kg} / \mathrm{m}^{2}$ (normal weight); $25.0-29.9 \mathrm{~kg} / \mathrm{m}^{2}$ (overweight); and $>30.0 \mathrm{~kg} / \mathrm{m}^{2}$ (obesity) 1. BMI was used as a continuous variable in the bivariate and multiple analysis. 


\section{Statistical analysis}

The data were analyzed separately for men and women, and the results were expressed initially as percentages, means, and confidence intervals $(95 \% \mathrm{CI})$. The frequencies of individuals in the different BMI categories (underweight, normal, overweight, and obesity) were calculated. To evaluate associations between study variables and the dependent variable (BMI), simple linear regression and Spearman analysis (specifically utilized for food consumption) were performed to estimate the independent effect of the control variables on the outcome (BMI), using hierarchical multiple linear regression analysis 17 . In addition to the variables showing significant association with $\mathrm{BMI}$, those with $\mathrm{p}<0.20$ according to the bivariate analysis were added to the multiple modeling procedure.

The World Health Organization theoretical model for obesity determinants 1 , as adapted to this study, served as a guideline to structure the blocks of variables and consequently the order in which these blocks entered the model. Block sequence: (1) socioeconomic and cultural variables (income, schooling, access to information on healthy eating); (2) demographic variables (age, parity in women, and marital status); (3) lifestyle (smoking and alcohol intake); (4) physical activity (at work, while commuting, leisure- time, and hours spent watching TV); and (5) eating habits (number of meals, meals in front of the TV, frequency of consumption of different food groups). In the hierarchical model, variables from one block are adjusted to the variables from blocks at preceding levels, as well as to variables from the same level 16 . Variables with $\mathrm{p}<0.05$ were kept in the model, while the others were used for adjustment purposes only.
All data were entered twice. Stata software, version 7.0 (Stata Corp., College Station, U.S.A.) was used for analysis. Statistical analyses were corrected by complex delineation of the sample, use of the set of svy commands that take the sample's complex structure into account. Sample weights associated with each sample cluster and the effect of the sampling design were incorporated into the analyses. A 5\% significance level was used.

\section{Results}

Of the 1,252 individuals studied, $35 \%$ were men ( $n=433)$ and $65 \%$ women $(n=819)$. The two groups did not show significant differences in schooling, income, age, or BMI (Table 1).

Approximately $42 \%$ of men showed excess weight (31.2\% overweight and $10.7 \%$ obese). However, only $26 \%$ presented above-normal abdominal adiposity. In women, some $43 \%$ presented both excess weight (29.2\% overweight and $13.9 \%$ obese) and increased abdominal adiposity (Table 2).

The prevalence rates for smoking, alcohol consumption, and sedentary habits during leisure time were $27.7 \%( \pm 2.4), 60.3 \%( \pm 3.1)$, and $50.7 \%( \pm 2.7)$ for men, and $19 \%( \pm 2.2), 37.9 \%$ $( \pm 2.1)$, and $71.1 \%( \pm 2.7)$ for women, respectively.

For men, bivariate analysis of age, income, presence of a spouse/partner, smoking cessation, and meat consumption were positively associated $(\mathrm{p}<0.05)$ with BMI. In contrast, vegetable consumption and leisure-time and commuting physical activity were inversely associated ( $\mathrm{p}<$ 0.05) with BMI. For women, age, parity, smoking cessation, change in diet in the previous year, use of sweeteners, and meat consumption were posi-

Table 1

Mean values and confidence intervals $(95 \% \mathrm{Cl})$ of selected variables for men and women. Goiânia, Goiás State, Brazil, 2001.

\begin{tabular}{|c|c|c|c|c|c|}
\hline \multirow[t]{2}{*}{ Variables } & \multicolumn{2}{|c|}{ Men $(n=433)$} & \multicolumn{2}{|c|}{ Women $(n=819)$} & \multirow[t]{2}{*}{$\mathrm{p}$} \\
\hline & Mean & $95 \% \mathrm{Cl}$ & Mean & $95 \% \mathrm{Cl}$ & \\
\hline Schooling (years) & 7.9 & $6.8 ; 8.9$ & 7.5 & $6.5 ; 8.5$ & 0.089 \\
\hline Income (in Reais - R\$) * & 361.2 & $262.2 ; 460.3$ & 293.5 & $220.4 ; 366.5$ & 0.050 \\
\hline Age (years) & 38.4 & $37.3 ; 39.5$ & 38.1 & $37.0 ; 39.1$ & 0.668 \\
\hline Weight (kg) & 70.7 & $68.0 ; 73.3$ & 61.3 & $60.0 ; 62.5$ & 0.000 \\
\hline Height (m) & 169.6 & $168.8 ; 170.4$ & 157.4 & $156.8 ; 157.9$ & 0.000 \\
\hline Body mass index $\left(\mathrm{kg} / \mathrm{m}^{2}\right)$ & 24.6 & $23.8 ; 25.3$ & 24.8 & $24.3 ; 25.3$ & 0.450 \\
\hline Waist circumference $(\mathrm{cm})$ & 86.3 & $84.0 ; 88.6$ & 78.6 & $77.7 ; 79.5$ & 0.000 \\
\hline
\end{tabular}

* In December 2001: R\$ $2.32=$ US\$1.00; in December 2005: R\$ $2.33=$ US\$1.00. 
Distribution of body mass index and waist circumference in men and women. Goiânia, Goiás State, Brazil, 2001.

\begin{tabular}{|c|c|c|c|c|c|c|}
\hline \multirow[t]{2}{*}{ Variables } & \multicolumn{3}{|c|}{ Men $(n=433)$} & \multicolumn{3}{|c|}{ Women $(n=819)$} \\
\hline & $\mathrm{n}$ & $\%$ & $95 \% \mathrm{Cl}$ & $\mathrm{n}$ & $\%$ & $95 \% \mathrm{Cl}$ \\
\hline \multicolumn{7}{|l|}{ Body mass index } \\
\hline Underweight & 13 & 3.9 & $1.5 ; 6.2$ & 49 & 6.5 & $3.8 ; 9.2$ \\
\hline Normal weight & 221 & 54.2 & $45.8 ; 62.6$ & 409 & 50.3 & $47.6 ; 53.1$ \\
\hline Overweight & 144 & 31.2 & $23.9 ; 38.3$ & 235 & 29.2 & $26.8 ; 31.7$ \\
\hline Obesity & 55 & 10.7 & $7.6 ; 13.8$ & 126 & 13.8 & $10.5 ; 17.4$ \\
\hline \multicolumn{7}{|l|}{ Waist circumference * } \\
\hline Adequate & 312 & 73.6 & $65.9 ; 81.4$ & 459 & 56.8 & $53.6 ; 60.0$ \\
\hline Increased & 73 & 16.6 & $12.2 ; 21.0$ & 183 & 23.4 & $21.0 ; 25.7$ \\
\hline Greatly increased & 47 & 9.4 & $5.2 ; 13.6$ & 173 & 19.6 & $17.0 ; 22.2$ \\
\hline
\end{tabular}

* Four women and one man lacked information on waist circumference.

tively correlated $(\mathrm{p}<0.05)$ with BMI. However, height, schooling, and consumption of alcoholic beverages, eggs, fat, grains, fruit, and sweets showed a negative association $(\mathrm{p}<0.05)$.

Variables with $\mathrm{p}<0.20$ in the bivariate analysis and which were added to the multiple regression analysis were: (for both men and women) food intake during the previous year, physical activity at work, number of meals, and the habit of eating meals in front of the TV; (for men only) alcohol consumption and dietary changes; and (for women only) leisure-time physical activity.

Tables 3 and 4 show the coefficients for the hierarchical multiple linear regression models that demonstrate the independent influence of sociodemographic variables, lifestyle, eating practices, and food consumption on BMI in men and women. For men, smoking and alcohol consumption remained as adjustment variables, since multiple regression analysis resulted in $\mathrm{p}<0.20$. The same occurred with the variables marital status and use of sweeteners in the women's model.

In men, BMI increased with age. Higher-income men showed a higher mean BMI than those in the lowest quartile. Leisure-time and commuting physical activities were inversely correlated with BMI. Consumption of 4 or more meals per day was also inversely associated with BMI; frequency of vegetable intake showed a slightly negative association $(p=0.09)$ and meat intake showed a positive association $(\mathrm{p}=0.01)$ with BMI (Table 3).

In women, BMI increased markedly and progressively with age; mean BMI in former smokers was higher than for non-smokers. Sedentary behavior (watching TV more than 6 hours/day) favored increased BMI, while frequency of grain consumption showed a negative association, as did diet change during the previous year. Meanwhile, meat consumption was positively associated with BMI (Table 4).

\section{Discussion}

The objectives of this study were to evaluate the prevalence of overweight and obesity and estimate associations between variables related to socio-demographic conditions, lifestyle, physical activity, eating habits, food consumption frequency, and BMI in a wide range of individuals.

The higher proportion of women in the sample might suggest a selection bias, but comparison of the distribution of this population according to age group and schooling with data supplied by the National Census Bureau 17 indicates that our sample is representative of the adult population of Goiânia.

The plain questionnaire on food frequency used in this study consisted of two components: a list of foods and preparations and the frequency with which they were consumed. Use of this type of questionnaire allowed the researchers to identify the frequency with which foods or food groups were consumed, without classifying individuals according to nutrient or energy consumption 19 .

Inclusion of portion sizes for each food item allowed estimating the nutrient content in a questionnaire on the food intake frequency. However, this is not an easy task, since the portion sizes must be determined in the respective study population, because standardized food portions represent convenience amounts 
Factors associated with body mass index according to hierarchical multiple linear regression in adult men. Goiânia, Goiás State, Brazil, 2001.

\begin{tabular}{|c|c|c|c|c|c|}
\hline Variables & $\beta$ (crude) & $95 \% \mathrm{Cl}$ & B (adjusted) & $95 \% \mathrm{Cl}$ & $p$ \\
\hline \multicolumn{6}{|c|}{ Age bracket (years) * } \\
\hline $20-24$ & - & - & - & - & - \\
\hline $25-34$ & 1.79 & $0.53 ; 3.06$ & 1.79 & $0.53 ; 3.06$ & 0.01 \\
\hline $35-44$ & 2.73 & $1.54 ; 3.92$ & 2.73 & $1.54 ; 3.91$ & $<0.01$ \\
\hline $45-54$ & 3.74 & $3.00 ; 4.47$ & 3.74 & $3.10 ; 4.47$ & $<0.01$ \\
\hline $55-64$ & 2.96 & $1.89 ; 4.02$ & 2.96 & $1.89 ; 4.02$ & $<0.01$ \\
\hline \multicolumn{6}{|l|}{ Income ** } \\
\hline 1st quartile & - & - & - & - & - \\
\hline 2nd quartile & 0.35 & $-1.06 ; 1.77$ & 0.32 & $-0.89 ; 1.53$ & 0.60 \\
\hline 3rd quartile & 0.58 & $-0.72 ; 1.88$ & 1.29 & $-0.18 ; 2.76$ & 0.08 \\
\hline $4^{\text {th }}$ quartile & 1.97 & $0.57 ; 3.36$ & 2.14 & $0.82 ; 3.44$ & $<0.01$ \\
\hline \multicolumn{6}{|c|}{ Leisure-time physical activity *** } \\
\hline Sedentary & - & - & - & - & - \\
\hline Light & 0.38 & $-0.69 ; 1.46$ & 0.54 & $-0.38 ; 1.47$ & 0.25 \\
\hline Moderate & -1.90 & $-2.77 ;-1.02$ & -1.18 & $-1.92 ;-0.45$ & $<0.01$ \\
\hline \multicolumn{6}{|c|}{ 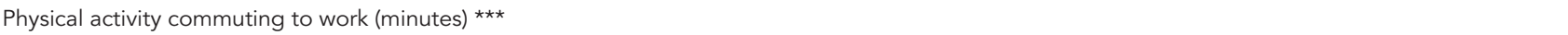 } \\
\hline$<15$ & - & - & - & - & - \\
\hline$\geq 15$ & -1.48 & $-2.17 ;-0.79$ & -1.14 & $-2.01 ;-0.27$ & 0.01 \\
\hline \multicolumn{6}{|c|}{ Number of meals per day \# } \\
\hline$<4$ & - & - & - & - & - \\
\hline$\geq 4$ & -0.59 & $-1.36 ; 0.16$ & -0.86 & $-1.50 ;-2.09$ & 0.01 \\
\hline Meat \# & 0.78 & $-0.36 ; 1.59$ & 1.11 & $0.45 ; 1.78$ & $<0.01$ \\
\hline
\end{tabular}

Variables with $p<0.05$ were kept in the model. The other values were maintained for adjustment purposes only.

* Model 1: age;

** Model 2: model $1+$ income;

*** Model 3: model 2 + smoking, alcohol intake, leisure-time physical activity, physical activity while commuting to work;

\# Model 4: model 3 + number of meals and frequency of meat and vegetable intake.

and approximations that do not generally correspond to the amounts normally consumed. Thus, use of a quantitative or semi-quantitative questionnaire requires prior studies on the instrument's reproducibility and validity in the target population 19. In this context, and for the current study to be economically viable and methodologically adequate, the researchers opted to study only the frequency of food consumption by using an appropriate methodology for analysis of this type of questionnaire on food intake frequency 14

The cross-sectional design does not allow determining exactly the time interval between the independent and dependent variables. Thus, one bias in cross-sectional studies is reverse causality 12 . Nevertheless, the design does show the prevalence and distribution of target variables and allows testing established hypotheses and proposing others for subsequent testing, employing more adequate designs.
The hierarchical form used in this study's multiple regression analysis is currently the most appropriate statistical methodology for testing the effect of contributing factors, according to precedence, on the outcome. This study employed a sample representing the urban area of the county of Goiânia, and the data were collected with household interviews by properly trained interviewers.

In the absence of previous data specific to the county of Goiânia, comparison with data from a prior nationwide study shows that in men the prevalence of overweight increased from 22.6 to $31.2 \%$ and obesity from 4.8 to $10.7 \%$. In women, the prevalence of overweight increased from 26.5 to $29.2 \%$ and obesity from 11.7 to $13.8 \% 3$.

For developing countries, the WHO recommends a mean BMI of $23 \mathrm{~kg} / \mathrm{m}^{2}$, while for developed countries the recommended mean BMI is $21 \mathrm{~kg} / \mathrm{m}^{2}$. In general, mean BMI is increasing in both sexes, at all schooling and income levels, and 
Factors associated with body mass index identified by hierarchical multiple linear regression in adult women. Goiânia, Goiás State, Brazil, 2001

\begin{tabular}{|c|c|c|c|c|c|}
\hline Variables & $\beta$ (crude) & $95 \% \mathrm{Cl}$ & $\beta$ (adjusted) & $95 \% \mathrm{Cl}$ & $p$ \\
\hline \multicolumn{6}{|l|}{ Age (years) * } \\
\hline $20-24$ & - & - & - & - & - \\
\hline $25-34$ & 0.90 & $0.23 ; 1.58$ & 0.68 & $-0.04 ; 1.40$ & 0.06 \\
\hline $35-44$ & 2.55 & $1.76 ; 3.35$ & 2.25 & $1.43 ; 3.07$ & $<0.01$ \\
\hline $45-54$ & 3.73 & $2.96 ; 4.49$ & 3.25 & $2.32 ; 4.17$ & $<0.01$ \\
\hline $55-64$ & 5.57 & $4.11 ; 7.03$ & 5.00 & $3.57 ; 6.43$ & $<0.01$ \\
\hline \multicolumn{6}{|l|}{ Smoking ** } \\
\hline Non-smoker & - & - & - & - & - \\
\hline Smoker & -0.74 & $-1.89 ; 0.40$ & -0.96 & $-2.20 ; 0.28$ & 0.13 \\
\hline Ex-smoker & 1.73 & $0.66 ; 2.80$ & 1.22 & $0.45 ; 2.00$ & $<0.01$ \\
\hline \multicolumn{6}{|c|}{ Hours watching TV/day *** } \\
\hline$<6$ & - & - & - & - & - \\
\hline$\geq 6$ & 2.29 & $-0.33 ; 4.90$ & 2.69 & $0.45 ; 4.92$ & 0.02 \\
\hline \multicolumn{6}{|c|}{ Change of diet in the last year \# } \\
\hline No & - & - & - & - & \\
\hline Yes & 1.52 & $0.86 ; 2.19$ & 1.15 & $0.59 ; 1.71$ & $<0.01$ \\
\hline Grains \# & -0.76 & $-1.00 ; 0.50$ & -0.62 & $-0.89 ;-0.35$ & $<0.01$ \\
\hline Meat \# & 0.58 & $-0.30 ; 1.60$ & 1.58 & $0.46 ; 2.69$ & $<0.01$ \\
\hline
\end{tabular}

Variables with $p<0.05$ were kept in the model. The other values were maintained for adjustment purposes only.

* Model 1: age, height;

** Model 2: model $1+$ marital status and smoking;

*** Model 3: model $2+$ hours watching TV/day;

\# Model 4: model 3 + diet change in the last year, use of sweeteners and frequency meat and grain consumption.

in all age brackets except the youngest. This highlights the relevance of obesity as a public health problem and the need to identify social and behavioral factors related to excess body weight.

As for socio-demographic variables, increased BMI went hand-in-hand with higher income for men only, corroborating the results of the 1989 National Survey on Health and Nutrition (PNSN) 3 and the POF 2002-2003 2. Some studies have indicated that excess weight and obesity are inversely correlated with socioeconomic status in developed countries 9,20,21, especially among women. However, in developing countries these characteristics are positively correlated with the population's socioeconomic status 8,22 .

A recent study 23 on the social distribution of obesity among 20-49-year-old women in 37 developing countries $(n=1,148,579)$ demonstrated that belonging to the lowest socioeconomic class provides strong protection against obesity in countries with low per capita gross national product (< US\$ 745), but is a strong risk factor in more developed economies (per capita GNP $\geq$ US\$2,995). It is important to note the high obe- sity prevalence among lower-income women, as has been demonstrated in selected urban areas of Brazil's Southeast, the country's most economically developed region 7,24 .

This study failed to show an association between BMI and schooling for either sex. Contrary to expectations, individuals with more schooling did not achieve better weight control, regardless of their presumed higher degree of knowledge on health and healthy eating habits.

Evidence from studies in developed countries 25,26,27 and findings for women in Southeast Brazil 7 both show a century-old trend, initially among women, of a negative association between schooling and BMI. This influence thus depends on the population's degree of development $8,22,26$, indicating that heterogeneous social and economic status gives rise to different situations, varying from increased risk to protection.

Other studies 28,29 have also failed to show a correlation between BMI and parity among women. BMI increased significantly with the number of children; however, this influence lost statistical significance after controlling for age. 
The presence of a spouse/partner can lead to changes in diet and physical activity that favor weight gain 30,31 . In this study, marital status was associated with obesity according to the bivariate analysis for men. However, the effect of this variable lost statistical significance after multiple regression analysis, following adjustment for socioeconomic variables.

Bivariate analysis showed a negative association, for both men and women, between alcohol consumption, regardless of the amount, and BMI. However, in contrast to the situation with alcoholics, moderate consumers of alcoholic beverages show a tendency to consume more energy than non-consumers 32 . Still, epidemiological studies show mixed results on the association between alcohol consumption and BMI 9,21,27,33.

We found no difference in BMI for smokers versus non-smokers, for either men or women. The association between BMI and smoking is controversial in epidemiological research, since some authors have observed an inverse association 31,34 , unlike others showing no such association 33 ; meanwhile, still other researchers have observed a positive association 35 .

These differences can be explained in part by the results of a study in the MONICA Project 36 , analyzing the extent and consistency of the association between smoking and BMI in 42 populations: in general, smokers, men or women, weighed less than individuals who had never smoked. Differences ranged from -2.4 to $0.5 \mathrm{~kg} / \mathrm{m}^{2}$ in men and -2.0 to $-0.1 \mathrm{~kg} / \mathrm{m}^{2}$ in women. These associations were less apparent in populations with a relatively low proportion of smokers and a high proportion of non-smokers, suggesting that over time the "classical" inverse association between BMI and smoking may lose strength in populations submitted to extensive anti-smoking campaigns (e.g., United States, Finland, and Australia) or in groups of smokers with unhealthy habits associated with weight gain, such as a sedentary behavior and higher fat intake.

In this study, former smokers of both sexes had higher BMI than non-smokers and current smokers. However, after multiple regression analysis the association only remained significant in women. This finding is consistent with a longitudinal study 37 indicating that women who stopped smoking gained more weight than men, although their contribution to increased obesity remained small or even absent 38 .

The method used here to evaluate the contribution of physical activity did not allow a more precise analysis of energy expenditure, mainly since it was unable to measure the number of hours spent per day in different kinds of physi- cal activity. Neither was the method able to take physical activity at home into account. Despite these limitations, an inverse correlation between BMI and leisure-time physical activity was observed in men, but not in women. This result agrees with those of other studies 21,39,40. The lack of association in women, although unexpected (since physical activity is an important contributor to energy expenditure), has also been observed in other studies 20,31,40.

No association was observed between BMI and occupational physical activity for either sex, which is consistent with other studies 21,38 . Nevertheless, data from NHANES III show that intense occupational physical activity can reduce the odds of obesity by half, especially for individuals with little or no leisure-time physical activity ${ }^{39}$. In this research the authors observed that physical activity at work mainly involves low energy expenditure, especially for women.

In the current study, most men used motor vehicles for commuting and had a higher mean BMI than those who walked or rode a bicycle. According to a study in Tianjin, one of the largest cities in China, men and women who walked or rode bicycles to work or during their leisure time had $50 \%$ less probability of excess weight, after adjusting for socio-demographic factors, lifestyle, food consumption, and physical activity at work 31 .

According to a cohort study ${ }^{9,41}$ on different types of sedentary behavior, watching TV for prolonged periods was a major risk factor for developing obesity and diabetes. For each two-hour increase in the time spent watching TV, there was a $23 \%$ (17-30; 95\%CI) risk of obesity 41 . In our study, multiple analyses showed that for women, watching TV for prolonged periods significantly raised their BMI. Women who watched more TV were less physically active during their leisure time and consumed fruits and vegetables less frequently than their more active counterparts ( $\mathrm{p}<0.001$, data not shown).

Regarding food frequency, for women, multiple regression analysis showed that only the consumption of grains (negative association) and meat (positive association) remained statistically significant. For men, only meat consumption showed a positive correlation. Similar results were observed in other cross-sectional studies on the consumption of grains, a major source of carbohydrates, and meat, an important source of fat and protein 21,31,42.

The lack of correlation between the frequency of consumption of sweets and BMI may reflect dietary changes by individuals with high BMI who are attempting to lose weight, but could also result from underreporting or even 
omission of information about the frequency of consumption of these foods, known to be highly caloric. Another possible explanation is that the amount of sweets consumed (rather than the frequency) makes up for the difference between the normal-weight and obese subjects studied. In the opposite direction, overestimating the frequency of consumption of low-energy food, such as fruits and vegetables, which result in a socially desired conduct, may also have occurred. Thus, the lack of an association between behavioral variables and BMI may suffer the influence of both the study design and biased information.

Along with excess calories, the number of daily meals appears to affect the regulation of body weight and lipogenesis, since obese individuals frequently tend to eat a great deal of food during a single meal, generally in the late afternoon or evening. However, the association between the number of meals and obesity has not been observed in every study 28 . In our case, the habit of having four or more meals per day was a protective factor against excess weight among men, a result that reinforced the premise that the eating pattern associated with obesity is irregular and/or disorganized. However, the habit of having one or more meals in front of the TV was not correlated with BMI in either sex.

This study demonstrates the prevalence of excess weight in the adult population of Goiânia. It identifies the factors independently associated with BMI. Prevalence of excess weight was high, with $41.9 \%$ of men (31.2\% overweight and $10.7 \%$ obese) and $43 \%$ of women $(29.2 \%$ overweight and $13.8 \%$ obese), increasing with age in both men and women, and with income in men only. Active lifestyle (among men) and consumption of grains (among women) and less meat appear to offer increased protection against higher BMI. Considering that excess weight is a risk factor for cardiovascular diseases, more aggressive public policies are needed to change this strong national trend in Brazil.

\section{Resumo}

Este estudo investigou a prevalência de obesidade e a associação de variáveis sócio-demográficas, estilo de vida, atividade física, comportamento alimentar $e$ freqüência de consumo alimentar, $e$ o índice de massa corporal (IMC) da população adulta de Goiânia, Goiás, Brasil. Estudo transversal de base populacional, em 2001, com 1.252 indivíduos de 20-64 anos. A associação entre as variáveis sócio-demográficas, estilo de vida, consumo alimentar e atividade física e o IMC foi avaliada por meio de análise de regressão linear múltipla hierarquizada. A prevalência de obesidade foi de 10,7\% (homens) e de 13,9\% (mulheres). Para os homens, idade, renda e consumo de carnes apresentaram associação positiva com IMC, enquanto que atividade física no lazer, atividade física no deslocamento para $o$ trabalho e o hábito de fazer $\geq 4$ refeições por dia apresentaram associação negativa. Para as mulheres, idade, abandono do tabagismo, tempo assistindo à TVe consumo de carnes apresentaram associação positiva, já o consumo de cereais apresentou associação negativa. Foi observada alta prevalência de obesidade; um estilo de vida ativo, ingestão de mais cereais e menos carnes, promoveram maior proteção contra a elevação do IMC.

Consumo de Alimentos; Atividade Física; Obesidade; Estilo de Vida

\section{Contributors}

M. R. G. Peixoto organized the databank and performed the statistical analyses. M. R. G. Peixoto, M. H. D'A. Benício, and P. C. B. V. Jardim worked jointly on the other stages of the project, including analysis of the results, the final draft, and review of the scientific paper.

\section{Acknowledgments}

The authors wish to thank the Brazilian National Research Council (CNPq) for its financial support. 


\section{References}

1. World Health Organization. Obesity: preventing and managing the global epidemic. Geneva: World Health Organization; 1997.

2. Instituto Brasileiro de Geografia e Estatística. Pesquisa de Orçamentos Familiares, 2002-2003. Excesso de peso atinge 38,8 milhões de brasileiros adultos. http://www.ibge.gov.br (accessed on 05/ Mar/2005)

3. Coitinho DC, Leão MM, Recine E, Sichieri R. Condições nutricionais da população brasileira: adultos e idosos: Brasília: Instituto Nacional de Alimentação e Nutrição; 1991.

4. Kannel WB, Brand N, Skinner Jr. JJ, Drawber TR, McNamara PM. The relation of adiposity to blood pressure and development of hypertension. The Framingham Study. Ann Intern Med 1967; 67:4859.

5. Manson JE, Colditz GA, Stampfer MJ, Willet WC, Rosner B, Monson RB, et al. A prospective study of obesity and risk of coronary heart disease in women. N Engl J Med 1990; 322:882-9.

6. Baik I, Ascherio A, Rimm EB, Giovannucci E, Spiegelman D, Stampfer MJ, et al. Adiposity and mortality in men. Am J Epidemiol 2000; 152:26470.

7. Monteiro CA, Conde WL. A tendência secular da obesidade segundo estratos sociais: Nordeste e Sudeste do Brasil, 1975-1989-1997. Arq Bras Endocrinol Metab 1999; 43:186-94.

8. Martorell R, Khan LK, Hughes ML, GrummerStrawn LM. Obesity in women from developing countries. Eur J Clin Nutr 2000; 54:247-52.

9. Liebman M, Pelican S, Moore SA, Holmes B, Wardlaw MK, Melcher LM, et al. Dietary intake, eating behavior, and physical activity-related determinants of high body mass index in rural communities in Wyoming, and Idaho. Int J Obes 2003; 27:684-92.

10. Jardim PCBV, Peixoto MRG, Monego ET, Moreira HG, Vitorino PVO, Souza WKSB, et al. Hipertensão arterial e alguns fatores de risco em uma capital brasileira. Arq Bras Cardiol 2007; 88:452-7.

11. Ministério da Saúde. Controle da hipertensão arterial: uma proposta de integração ensino-serviço. Brasília: Ministério da Saúde; 1993.

12. Hulley BH, Cummings SR. Designing clinical research: an epidemiological approach. Baltimore: Williams and Wilkins; 1988.

13. Organización Panamericana de la Salud. Protocolo y directrices: conjunto de acciones para la Reducción Multifactorial de Enfermedades no Transmisibles (CARMEN/CINDI). Washington DC: Organización Panamericana de la Salud; 1997.

14. Fornés NS, Martins IS, Velásquez-Meléndez G, Latorre MRDO. Escores de consumo alimentar e níveis lipêmicos em população de São Paulo, Brasil. Rev Saúde Pública 2002; 36:12-8.

15. Gil MF, Braga VLN, Cunha DTO, Monego ET, Reis MAC, Moreira MA, et al. Freqüência alimentar, estado nutricional, atividade física e renda familiar em Goiânia - dados preliminares. In: Anais do V Congresso Brasileiro de Saúde Coletiva. Rio de Janeiro: ABRASCO; 1997. p. 317.
16. Lohman TG, Roche AF, Martorel R. Anthropometric standardization reference manual. Champaign: Human Kinetics Books; 1988.

17. Victora CG, Huttly S, Fuchs SC, Olinto MT. The role of conceptual frameworks in epidemiological analysis: a hierarchical approach. Int J Epidemiol 1997; 26:224-7.

18. Instituto Brasileiro de Geografia e Estatística. Censo demográfico 2000. http://www.ibge.gov.br (accessed 02/Jun/2003).

19. Willet W. Nutritional epidemiology. 2nd Ed. New York: Oxford University Press; 1998.

20. Wamala SP, Wolk A, Orth-Gomer K. Determinants of obesity in relation to socioeconomic status among middle-aged Swedish women. Prev Med 1997; 26(5 Pt 1):734-44.

21. Lahti-Koski M, Pietnen P, Heliovaara M, Vartiainen E. Associations of body mass index and obesity with physical activity, alcohol intake, and smoking in the 1982-1997 FINRISK studies. Am J Clin Nutr 2002; 75:809-17.

22. Molarius A, Seidell JC, Sans S, Tuomilehto J, Kuulasmaa K. Educational level, relative body weight, and changes in their association over 10 years: an international perspective from the WHO MONICA Project. Am J Public Health 2000; 90:1260-8.

23. Monteiro CA, Conde WL, Lu B, Popkin BM. Obesity and inequities in health in the developing world. Int J Obes 2004:1-6.

24. Monteiro CA, Conde WL, Popkin BM. Independent effects of income and education on the risk of obesity in the Brazilian adult population. J Nutr 2001; 131:881S-6S.

25. Rissanen AM, Heliövaara M, Knekt P, Reunanen A, Aromaa A. Determinants of weight gain and overweight in adult Finns. Eur J Clin Nutr 1991; 45:41930.

26. Gutiérrez-Fisac JF, Regidos E, Rodriguez C. Trends in obesity differences by educational level in Spain. J Clin Epidemiol 1996; 49:351-4.

27. Mokdad AH, Bowman BA, Ford ES, Vinicor F, Marks JS, Koplan JP. The continuing epidemics of obesity and diabetes in the United States. JAMA 2001; 286:1195-200.

28. Gigante DP, Barros FC, Post CLA, Olinto MTA. Prevalência de obesidade em adultos e seus fatores de risco. Rev Saúde Pública 1997; 31:236-46.

29. Kruger HS, Venter CS, Voster HH, Margetts BM. Physical inactivity is the major determinant of obesity in black women in the North West Province, South Africa: the THUSA study. Nutrition 2000; 18:422-7.

30. Woo J, Leung SSF, Ho SC, Sham A, Lam TH, Janus ED. Influence of educational level and marital status on dietary intake, obesity and other cardiovascular risk factors in a Hong Kong Chinese population. Eur J Clin Nutr 1999; 53:461-7.

31. Hu G, Pekkarinen H, Hänninen O, Tian H, Jin R. Comparison of dietary and non-dietary risk factors in overweight and normal-weight Chinese adults. Br J Nutr 2002; 88:91-7. 
32. Westerterp-Plantenga MS, Verwegen CR. The appetizing effect of an aperitif in overweight and normal-weight humans. Am J Clin Nutr 1999; 69:20512.

33. Colditz GA, Giovannucci E, Rimm EB, Stampfer MJ, Rosner B, Speizer FE, et al. Alcohol intake in relation to diet and obesity in women and men. Am J Clin Nutr 1991; 54:49-55.

34. Eck LH, Hackett-Renner C, Klesges LM. Impact of diabetic status, dietary intake, physical activity, and smoking status on body mass index in NHANES II. Am J Clin Nutr 1992; 56:329-33.

35. Marti B, Tuomilehto J, Korhonen HJ, Kartovaara L, Vartiainen E, Pietinen P, et al. Smoking and leanness: evidence for change in Finland. BMJ 1989; 298:1287-90.

36. Molarius A, Seidell JC, Kuulasmaa K, Dobson AJ, Sans S. Smoking and relative body weight: an international perspective from the WHO MONICA Project. J Epidemiol Community Health 1997; 51:252-60.

37. Willianson DF, Madans J, Anda RF, Klieinman JC, Giovino GA, Byers T. Smoking cessation and severity of weight gain in a national cohort. $\mathrm{N}$ Engl J Med 1991; 324:739-45.
38. Artalejo FR, García EL, Gutiérrez-Fisac JL, Banegas JRB, Urdinguio PJL, Rojas VD. Changes in the prevalence of overweight and obesity and their factors in Spain, 1987-1997. Prev Med 2002; 34:72-81.

39. King GA, Fitzhugh EC, Basset Jr. DR, McLaughlin JE, Strath SJ, Swartz AM, et al. Relationship of leisure-time physical activity and occupational activity to the prevalence of obesity. Int J Obes 2000; 25:606-12.

40. Maddah M, Eshraghian MR, Djazayery A, Mirdamadi R. Association of body mass index with educational level in Iranian men and woman. Eur J Clin Nutr 2003; 57:819-23.

41. Hu FB, Li TY, Colditz GA, Willet WC, Manson JE. Television watching and other sedentary behaviors in relation to risk of obesity and type 2 diabetes mellitus in women. JAMA 2003; 289:1785-91.

42. Slaterry ML, McDonald A, Bild DE, Caan BJ, Hilner JE, Jacobs Jr. DR, et al. Associations of body fat and its distribution with dietary intake, physical activity, alcohol, and smoking in blacks and whites. Am J Clin Nut 1992; 55:943-9.

Submitted on 27/Dec/2005

Final version resubmitted on 18/Sep/2006 Approved on 15/Feb/2005 